\title{
Bipolar disorder in young people: divalproex sodium no more effective than lithium for maintenance
}

Findling RL, McNamara NK, Youngstrom EA, et al. Double-blind 18-month trial of lithium versus divalproex maintenance treatment in pediatric bipolar disorder. J Am Acad Child Adolesc Psychiatry 2005;44:409-17.

\section{$Q$ Is divalproex more effective than lithium as a monotherapy for young people with bipolar disorder who are stabilised on lithium plus divalproex?}

METHODS

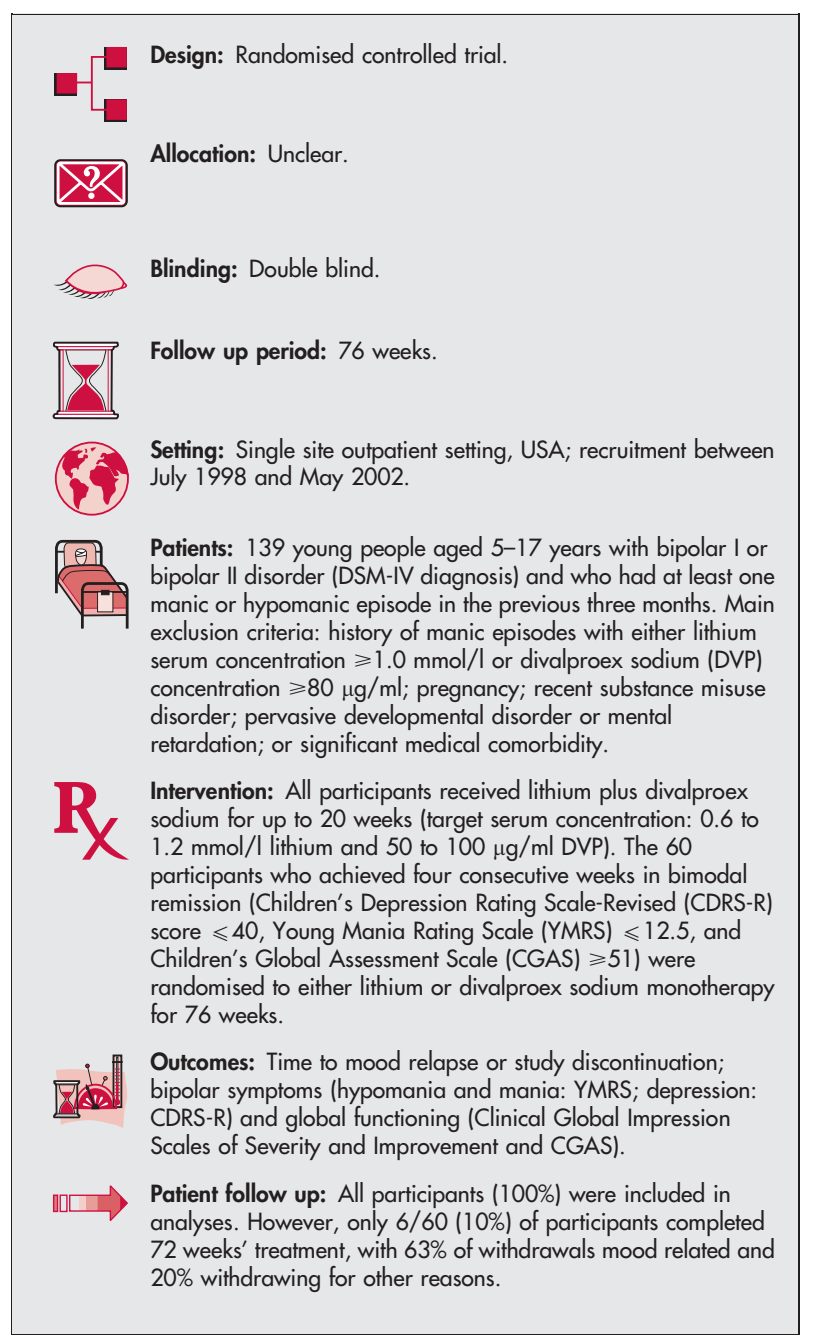

\section{MAIN RESULTS}

Lithium and divalproex groups did not differ in time to mood relapse (median: 114 days with lithium $v 112$ days with DVPX; $\mathrm{p}=0.55$ ) or time to study discontinuation for any reason (median: 91 days with lithium $v 56$ days with DVPX; $\mathrm{p}=0.72$ ). Bipolar symptoms and global functioning worsened in both treatment groups; there were no significant differences between treatments $(\mathrm{p}>0.37$ for all

For correspondence: Dr Findling, Director of Child and Adolescent Psychiatry, University Hospitals of Cleveland, 11100 Euclid Avenue, Cleveland, OH 44106-5080, USA; robert.findling@uhhs.com

Sources of funding: supported primarily by the Stanley Medical Research Institute and in part by a grant from the NIMH Developing Centres for Interventions and Services. comparisons). Compared with divalproex, lithium increased emesis $(30 \% \vee 10 \% ; \mathrm{p}=0.05)$, enuresis $(30 \% \vee 6.7 \% ; \mathrm{p}=0.05)$, and thirst $(16.7 \% \vee 0 \% ; \mathrm{p}=0.02)$. More people taking divalproex reported headache or stomach pain than with lithium, but the difference was not significant $(\mathrm{p}>0.1$ for both).

\section{CONCLUSIONS}

Divalproex sodium is not superior to lithium as a maintenance treatment for young people with bipolar disorder who have been stabilised on a combination of lithium plus divalproex sodium.

\section{Commentary}

The effectiveness of lithium and divalproex (DVP) alone in the acute treatment of mania in adults is well known. ${ }^{1}$ However, in children and adolescents there are as yet no published placebo controlled treatment studies for acute mania.

The study by Findling et al used a discontinuation approach to examine whether lithium or DVP is better at maintaining stabilisation in young people with bipolar disorder. The initial sample included 5-17 year olds who could tolerate and did not have a history of non-response to lithium or DVP. Children were treated from the outset on combined medication. Unlike other bipolar samples, ${ }^{2} 330 \%$ had no psychiatric comorbidity, or had mainly attention deficit hyperactivity disorder (ADHD), not oppositional defiant or anxiety disorders. About one third of the sample responded to the combined drug given openly. Responders' mean mania scores dropped to virtually zero, function scores improved very significantly, and response was maintained for four weeks to be eligible for discontinuation to only one medication. The study addressed maintenance on a single "mood stabiliser" and, somewhat by extension, effectiveness of either medication alone in treatment of acute mania in young people.

Without a placebo control, and/or a treatment arm that continued combined medication, we do not know whether single drug maintenance was better than nothing, or if combined treatment would have continued to work. We do know only 10\% "survived" on single drug, it did not matter which; half the sample relapsed mostly into mania or dropped out by three months. The same study in adults also found participants relapsed mostly into depression on a single drug (although more adults had bipolar II than bipolar I disorder). ${ }^{4}$

The aforementioned limitations preclude a definitive stance on the utility of single lithium or divalproex for acutely or longitudinally manic children. However, if the rush to diagnose children with bipolar disorder is meant to justify single mood stabiliser treatment, there is little encouragement to do so from these data.

Gabrielle A Carlson, MD Stony Brook University School of Medicine, Department of Psychiatry, Stony Brook, New York, USA

1 American Psychiatric Association. Practice Guideline for the treatment of patients with bipolar disorder (revision). Am J Psychiatry 2002;159(Suppl 4): $1-50$.

2 Tillman R, Geller B, Bolhofner K, et al. Ages of onset and rates of syndromal and subsyndromal comorbid DSM-IV diagnoses in a prepubertal and early adolescent bipolar disorder phenotype. J Am Acad Child Adolesc Psychiatry 2003;42:1486-93.

3 Biederman J, Faraone SV, Wozniak J, et al. Further evidence of unique developmental phenotypic correlates of pediatric bipolar disorder: findings from a large sample of clinically referred preadolescent children assessed over the last 7 years. J Affect Disord 2004;82:S45-58.

4 Calabrese JR, Shelton MD, Rapport DJ, et al. A 20-month, double-blind, maintenance trial of lithium vs. divalproex in rapid-cycling bipolar disorder. Am J Psychiatry (in press). 